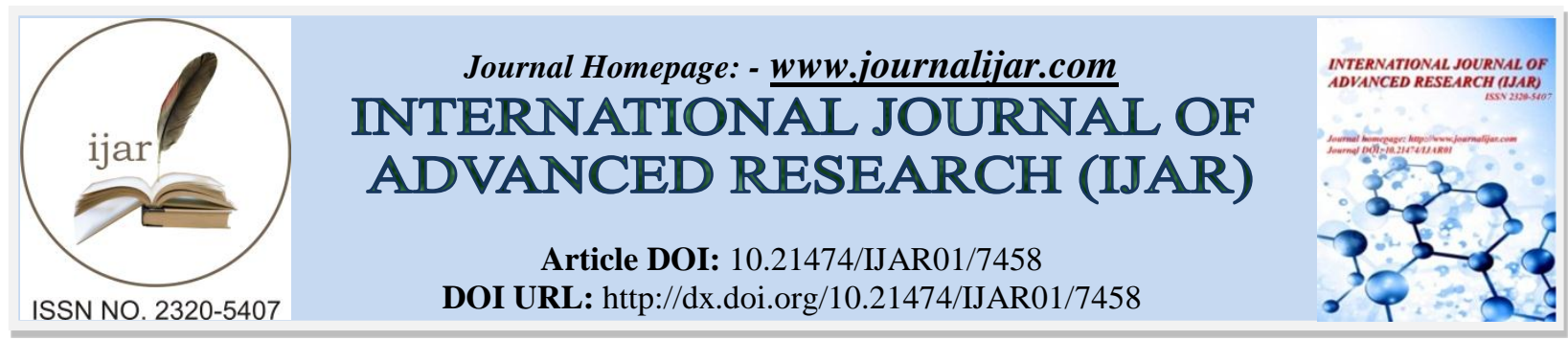

RESEARCH ARTICLE

\title{
COMPARATIVE EVALUATION OF TRANSVAGINAL SALINE SONOSALPINGOGRAPHY AND LAPROSCOPY FOR TUBAL PATENCY IN INFERTILITY.
}

\author{
Dr. Saima Sadiq. \\ Senior Resident, Department of Obstetrics and Gynecology, Lalla Ded hospital, Government Medical College, \\ Srinagar.
}

\section{Manuscript Info}

Manuscript History

Received: 21 May 2018

Final Accepted: 23 June 2018

Published: July 2018

Keywords:-

tubal patency, laproscopy, transvaginal

saline sonosalpingography, infertility.

\section{Abstract}

Background: There has been a drastic increase in the number of cases presenting with infertility and a shift in major causes from ovarian and uterine anomalies to tubal factors. Thus it was necessary to develop better means of evaluation of fallopian tubes. The technological advancements in the field of radiology made it possible to introduce into clinical practice sonographic assesment of fallopian tubes. During the past few years, sonosalpingography has been suggested as the firstline method to study tubal patency. This study was done to know the applicability of this method at our institution.

Objective: To compare transvaginal saline sonosalpingography (SSG) with laparoscopy for tubal patency in infertile patients in terms of sensitivity, specificity, positive predictive value (PPV) ,negative predictive value (NPV), false positives, false negatives, diagnostic accuracy, limitations and complications and to detect additional pelvic pathology.

Design: Diagnostic test (prospective cross sectional study).

Material and methods: Tubal patency of 50 infertile women with previous unknown tubal function

was assessed by transvaginal saline SSG on day $7^{\text {th }}$ or $8^{\text {th }}$ of menstrual cycle by injecting 10-30 $\mathrm{ml}$ of normal saline solution into the uterine cavity through a pediatric $8 \mathrm{~F}$ Foleys catheter. The collection of free fluid imaged in the pouch of Douglas or an increased volume of pre existing free fluid were considered as the evidence of at least unilateral tubal patency(positive test). Bilateral tubal obstruction was diagnosed by the absence of fluid collection or static level of fluid in pouch of Douglas( negative test) .Other positive findings were recorded. Diagnostic laparoscopy with chromopertubation was performed in the secretory phase of the same menstrual cycle of the same patient..

Results: The results from transvaginal saline SSG were compared to the findings from the standard diagnostic laparoscopy with chromopertubation. Transvaginal saline SSG had sensitivity, specificity, PPV, NPV and accuracy of $2.31 \%, 90.91 \%, 97.30 \%, 76.92 \%$ and $92 \%$. There was 1 false positive and 3 false negatives. Chi. square test detected the difference to be insignificant $(\mathrm{p}$ value $=0.74)$. Transvaginal saline SSG identified abnormal findings in $30 \%$ patients: most common being polycystic 
ovaries (8\%) followed by intramural myoma(6\%), adnexal mass (6\%),submucous myoma (4\%), endometrial polyp (2\%),incomplete uterine $\operatorname{septum}(2 \%)$ and simple ovarian cyst(2\%). Laparoscopy revealed abnormal findings in $50 \%$ patients : most common being endometriosis $(12 \%)$ followed by hydrosalpinx $(10 \%)$, polycystic ovaries $(8 \%)$, functional ovarian cyst $(8 \%)$ myoma $(6 \%)$ and adhesions $(6 \%)$. Adverse events of transvaginal saline SSG included mild pelvic pain during injection of saline through the uterine cavity in 30 patients $(60 \%)$. This did not, however, result in stopping the procedure or required any medication. No other immediate or remote complication was encountered by either transvaginal saline SSG or laproscopy.

Conclusion: The results confirm that transvaginal saline SSG is a simple, well tolerated and reliable screening method for the assessment of tubal patency in an outpatient setting with minimal adverse effect. However, other confirmatory tests are required whenever bilateral tubal occlusion is suspected due to possible false negative findings.

Copy Right, IJAR, 2018,. All rights reserved.

\section{Introduction:-}

Having a child of her own is the most intense desire and right of every woman. Inability to conceive can devastate her emotionally, socially and financially. If a couple fails to achieve pregnancy after one year of "unprotected" and regular intercourse, it is an indication to investigate the couple ${ }^{1}$. This is based on the observation that $80 \%$ of normal couples achieve conception within a year ${ }^{1}$.

Infertility is defined as a failure to conceive within one or more years of regular unprotected coitus ${ }^{2}$. Infertility is termed primary if conception has never occurred and secondary if the patient fails to conceive after having achieved a previous conception ${ }^{1}$. The incidence of infertility in any community varies between $5-15 \%$. The etiological factor is found in males in 30-40\% and in females in $40-55 \%{ }^{2}$. It may be found in both in $10 \%$ and may be unexplained in $10 \%^{2}$. According to International Federation of Gynaecology and Obstetrics (FIGO) manual (1990) female causes are - tuboperitoneal factors (25-35\%), ovulatory factor (30-40\%), endometriosis (1-10\%), uterine factor (10\%) and cervical factor $(5 \%)^{2}$.

Over the past 20 years there has been a shift in the causes of infertility, passing from the ovarian and uterine factors, to tubal factors. The incidence of tubal disease in infertility varies from country to country. In India it is estimated to be about $40 \%{ }^{3}$.

The increasing proportion of tubal infertility is due to the increasing frequency of tubal and pelvic surgeries, ectopic pregnancies, use of intrauterine contraceptive devices, and the more and more frequent pelvic inflammatory disease (PID). Pelvic inflammatory disease is the most common cause of tubal disease representing more than $50 \%$ of cases $^{4,5}$. After one episode of PID, rate of infertility has been estimated at $11 \%$ which increases to $23 \%$ and $54 \%$ after 2 and 3 episodes respectively ${ }^{6}$.

Probably the earliest known contribution to diagnostic evaluation of tubal pathology was that of "Hysterosalpingography" (HSG) introduced by Cary in $1914^{7}$ who injected radio-opaque medium and followed its course through the fallopian tubes by x-ray photography. The transvaginal technique was introduced in 1989 by Deichert et al. ${ }^{8}$, who used an echogenic medium in order to assess tubal patency and offer structural information. Tufekci et al. developed an easier technique, using isotonic saline solution'. They named it transvaginal sonohysterosalpingography (SHSG) or saline infusion salpingography (SIS). Furthermore, pelvic sonogram by transabdominal or transvaginal route provides complete examination of the entire pelvis, thus delineating uterine and ovarian abnormalities ${ }^{10}$.

For all these reasons, transvaginal saline sonosalpingography seems to be a very handy technique, avoiding invasive procedures in some patients, or optimizing the preoperative triage process for those women who require therapeutic intervention. So the present study was done to find the accuracy and applicability of this method, keeping laparoscopy as the gold standard. 


\section{Material And Methodology:-}

After obtaining the ethical clearance from the Institutional Ethical Committee, this observational study was conducted in the Department of Obstetrics and Gynaecology, Government Medical College, Srinagar on 50 infertile patients.

\section{Inclusion Criteria:-}

Patients who failed to conceive after one or more years of unprotected regular coitus.

\section{Exclusion Criteria:-}

1. Patients with developmental defects like Turner syndrome and Mullerian agenesis.

2. Patients who had any contraindication to sonosalpingography (pelvic infection or bleeding) or laparoscopy.

After taking detailed history, general physical examination and systemic examination was done and patients were subjected to the tests as per the proforma. Transvaginal saline sonosalpingography was done between day $7^{\text {th }}$ to $10^{\text {th }}$ day of menstrual cycle and diagnostic laparoscopy with chromopertubation was done in the secretory phase between $21^{\text {st }}$ to $25^{\text {th }}$ day of the same cycle in the same patient.

The whole data was assimilated in the form of a master chart. The validity and feasibility of transvaginal saline sonosalpingography was determined keeping laparoscopic chromopertubation as the gold standard.

Patients were put on antibiotics 2 days prior to the procedure. The procedure was explained to the patient and consent was taken. Patients were advised to empty the bladder prior to the procedure, placed in lithotomy position and bimanual examination was done. A preliminary transvaginal sonography was performed to assess any free fluid in the pouch of Douglas as baseline data and note additional findings like uterine size, gross lesions of endometrium, uterine cavity and myometrium, endometrial thickness and adnexal pathology if any. A sterile Sims speculum was introduced into the vagina, exposing the ectocervix, which was disinfected with an antiseptic solution. Next the tip of 8F Foley's catheter was introduced into the cervical canal and the lower uterine cavity, holding the cervix with the vulsellum. Following insertion of catheter, balloon was inflated with $2-3 \mathrm{ml}$ of normal saline. The catheter was pulled downward to ensure satisfactory balloon distension, avoiding catheter expulsion. The speculum and vulsellum were removed and vaginal probe introduced. While scanning, distention was carried out with 10-30ml of normal saline instilled into the uterine cavity and tubes through $8 \mathrm{~F}$ Foleys catheter. The collection of fluid in the pouch of Douglas or an increased volume of pre existing free fluid were considered as the evidence of at least unilateral tubal patency (positive test). Bilateral tubal obstruction was diagnosed by the absence of fluid collection or static level of pre-existing fluid in the pouch of Douglas (negative test). Other positive findings of the uterine cavity and adnexae were noted. After this patients were observed for 30 minutes and then sent home on oral antibiotics for a total of 5 days. They were called again for laparoscopy in the secretory phase between $21^{\text {st }}$ to $25^{\text {th }}$ day of the same cycle.

The statistical analysis of the data was done using McNemar's and Chi-square test. The tests were referenced for $p$ values and a $\mathrm{p}$ value less than 0.05 was taken as significant. The analysis of the data was performed by using SPSS computer program (Statistical Package for Social Sciences) Ver. 16.0.

\section{Observations And Results:-}

Out of 50 cases, the maximum number of cases i.e. 24 (48\%) were in 31-35 years age group, 17 cases (34\%) were in > 36 years age group and 9 cases (18\%) in 26-30 years age group. Out of 34 patients of primary infertility, maximum number of cases i.e. $19(55.9 \%)$ were in 31-35 years age group, $8(23.5 \%)$ cases were in 26-30 years age group and $7(20.6 \%)$ in $>36$ years age group. Out of 16 patients of secondary infertility, maximum number of cases i.e. $10(62.5 \%)$ were in $>36$ years age group, 5 cases $(31.2 \%)$ were in $31-35$ years age group and $1(6.2 \%)$ in $26-30$ years age group.

Out of total 50 infertile patients, 34 patients (68\%) had primary infertility and $16(32 \%)$ had secondary infertility. Out of 16 patients of secondary infertility, maximum i.e. 6 patients were para 1, abortion 1 (P1A1), followed by 5 patients who were para 1,2 patients who were abortion 2, 1 patient each as para 2, para 2, abortion 1 (P2A1), abortion 3. On transvaginal saline sonosalpingography, out of 34 cases of primary infertility, tubes were patent [(unilateral (UL) or bilateral (B/L)] in $30(88.24 \%)$ cases and blocked $(\mathrm{B} / \mathrm{L})$ in 4 cases $(11.76 \%)$ and in secondary 
infertility group, out of 16 cases, tubes were patent (U/L or B/L) in $7(43.75 \%)$ cases and blocked (B/L) in 9 cases $(56.25 \%)$. In the primary infertility group, out of 34 cases, laparoscopy with chromopertubation showed tubal patency in 31 cases $(91.18 \%)$ and tubal block in 3 cases $(8.82 \%)$ and out of 16 cases of secondary infertility, laparoscopy with chromopertubation showed tubal patency in 8 cases (50\%) and tubal block in 8 cases $(50 \%)$. 31 patients i.e. $29 \mathrm{TP}$ (patent $\mathrm{U} / \mathrm{L}$ or $\mathrm{B} / \mathrm{L}$ ) and $2 \mathrm{TN}$ (blocked B/L) had similar tubal findings on saline sonosalpingography and laparoscopy. In 2 patients false negative results were elicited i.e. tubes were blocked on sonosalpingography but patent on laparoscopy. In 1patient we got false positive result i.e. patent tubes on sonosalpingography but blocked on laparoscopy. 15 patients i.e. 7 TP (patent U/L or B/L) and 8 TN (blocked B/L) had similar tubal findings on saline sonosalpingography and laparoscopy. In 1 patient false negative results were elicited i.e., tubes were blocked (B/L) on sonosalpingography but patent on laparoscopy.

Out of total 50 cases, 37 cases (74\%) showed patent tubes (unilateral or bilateral) i.e. positive test and 13 cases (26\%) showed tubal block i.e. negative test. laparoscopic chromopertubation confirmed tubal patency (U/L or B/L) in 39 cases $(78 \%)$ and tubal block (B/L) in 11 cases $(22 \%) .46$ patients i.e. 36 TP (patent U/L or B/L) and 10TN (blocked B/L) had similar tubal findings on saline sonosalpingography and laparoscopy. In 3 patients false negative results were elicited i.e., tubes were blocked on sonosalpingography but patent on laparoscopy. In 1patient we got false positive result i.e. patent tubes on sonosalpingography but blocked on laparoscopy. Out of 11 patients who were confirmed as having tubal block in our study, sono salpingography detected adnexal mass in only 2 patients both of which on laparoscopy proved to be bilateral hydrosalpinx. 9 out of these 11 had positive finding on laparoscopy i.e. bilateral hydrosalpinx in 4, adhesions in 3, endometriosis in 1 and both bilateral hydrosalpinx and endometriosis in 1.2 out of 3 false negatives had intramural fibroid picked on both transvaginal saline sonosalpinography and laparoscopy.

Tubal block was more common in secondary infertility group with a p value of 0.004 and in patients from rural areas ( $\mathrm{p}$ 0.037). Transvaginal saline sonosalpingography identified additional findings in 15 patients (30\%): most common being polycystic ovaries in $4(8 \%)$ followed by intramural fibroid in $3(6 \%)$, adnexal mass in 3 (6\%), submucous fibroid in $2(4 \%)$, endometrial polyp in $1(2 \%)$, incomplete uterine septum in $1(2 \%)$ and ovarian cyst in $1(2 \%)$. Laparoscopy revealed additional findings in $50 \%$ patients: most common being endometriosis in 6 (12\%) followed by bilateral hydrosalpinx in $5(10 \%)$, polycystic ovaries in $4(8 \%)$, ovarian cyst in $4(8 \%)$, intramural myoma in 3 $(6 \%)$ and adhesions in $3(6 \%)$. Submucous fibroid, endometrial polyp and uterine septum was diagnosed only on transvaginal saline sonography whereas adhesions and endometriosis were detected exclusively by laparoscopy.

\section{Discussion:-}

With respect to various causes of infertility, tubal factor is one possibility that needs to be assessed during infertility work up. Traditionally, the assessment of tubal patency has been made by insufflating the fallopian tubes with carbon dioxide gas (Rubin test) ${ }^{11}$.

The present study was done on 50 infertile patients attending the OPD in the Department of Gynaecology and Obstetrics at Lalla Ded Hospital Srinagar. They were evaluated for tubal patency and additional pathology if any, by transvaginal saline sonosalpingography and laparoscopic chromopertubation. The age of the patients in our study ranged from 26 years to 38 years with the average age of $33+3.46$ years and this correlates with the study done by Junjira Suttipichate et al $(2002)^{12}$ in which the average age of the patients was $33.61+3.59$ years. 24 (48\%) patients in our study were in the 31-35 years age group, 17 (34\%) patients in 36 years and above age group and 9 (18\%) patients in 26-30 years age group. The maximum age in primary as well as secondary infertility group was 38 years whereas the minimum age in primary infertility group was 26 years and in secondary infertility group was 29 years. The average age in primary infertility group was $32.1+3.45$ years whereas in secondary infertility group was $34.9+2.63$ years. In the study by Nabil M et al $(2011)^{13}$ mean age in primary infertility group was $27.6+4.25$ years and in secondary infertility group was $29.8+4.1$ years.

We had $34(68 \%)$ primary infertility patients whereas $16(32 \%)$ patients had secondary infertility and this corresponds with many studies including the study by Seal Subrati Lall et al (2007) ${ }^{14}$ in which $73 \%$ patients had primary infertility and $27 \%$ had secondary infertility.

On transvaginal saline sonosalpingography, out of total 50 cases, 37 cases showed positive test i.e. patent tubes (unilateral or bilateral) and 13 cases showed negative test i.e. tubal block (bilateral) whereas on laparoscopy tubes were patent (unilateral or bilateral) in 39 cases and blocked (bilateral) in 11 cases. Therefore, tubes were patent in 
$74 \%$ patients on transvaginal sonosalpingography but laparoscopy confirmed it in $78 \%$ patients. Although tubal block was seen in $26 \%$ patients on transvaginal sonosalpingography, laparoscopy confirmed it in $22 \%$ patients in our study. Our results correspond with the study conducted by De Almeida L et al study (2000) ${ }^{15}$, in which $80 \%$ patients had patent tubes (unilateral or bilateral) and $20 \%$ patients had blocked tubes (bilateral) on transvaginal sonosalpingography and on comparing with laparoscopy it was seen that $83.33 \%$ patients had patent tube (unilateral or bilateral) and $16.67 \%$ patients had blocked tubes (bilateral).

Out of 50 patients, 46 patients had similar findings regarding tubal patency on transvaginal saline sonosalpingography and laparoscopy. These included 36 true positives i.e. patent tubes (unilateral or bilateral) on both procedures and 10 true negatives i.e. blocked tubes (bilateral) on both procedures. Therefore, the accuracy of transvaginal saline sonosalpingography with laparoscopy as the gold standard was $92 \%$ and this correlates with many studies including the study done by Nabil M et al (2011) ${ }^{13}$ in which diagnostic accuracy of transvaginal saline sonosalpingography was $94.1 \%$. Our results are also comparable with the study done by Junjira Suttipichate et al $(2002)^{12}$ where diagnostic accuracy of transvaginal saline sonosalpingography was $95.24 \%$. Likewise Zuo W et al $(1996)^{16}$ found transvaginal saline sonosalpingography as $87.1 \%$ accurate and Kore S et al ${ }^{3}(2000)$ revealed $97 \%^{2}$ accuracy are consistent with other studies including Junjira Suttipichate et al $(2002)^{12}$ in which out of 42 patients, there was one false positive and one false negative. In the study by Seal Subrata Lall et al (2007) ${ }^{14}$, out of 100 patients, there were 2 false positive and 2 false negative on transvaginal saline sonosalpingography.

In evaluation of tubal patency, with laparoscopy as the gold standard, transvaginal saline sonolpingography had a sensitivity of $92.31 \%$, specificity of $90.91 \%$, positive predictive value of $97.30 \%$, negative predictive value of $76.92 \%$ and diagnostic accuracy of $92 \%$ in our study. This is comparable with the study by Junjira Suttipichate et al $(2002)^{12}$ where transvaginal saline sonosalpingography compared with laparoscopy for tubal patency had sensitivity, specificity, PPV, NPV and diagnostic accuracy of 96.97\%, 88.89\%, 96.97\%, 88.89\% and 95.24\% respectively.

Transvaginal saline sonosalpingography identified additional findings in $15(30 \%)$ patients in our study: most common being polycystic ovaries in $4(8 \%)$ patients followed by intramural fibroid in $3(6 \%)$, adnexal mass in 3 $(6 \%)$, submucous fibroid in $2(4 \%)$, endometrial polyp in $1(2 \%)$, incomplete uterine septum in 1 (2\%) and ovarian cyst in $1(2 \%)$. Phillippe Jeanty et al in (2000) $)^{17}$ in their study of 115 patients diagnosed polyps in 9 , synechiae in 3, submucous fibroid in 2 patients and intramural fibroid in 1 patient with transvaginal saline sonosalpingography. Fleischer A C et al (1997) ${ }^{18}$, with transvaginal saline sonosalpingography diagnosed submucosal fibroid with $98 \%$ accuracy, polyp with $96 \%$ accuracy and synechiae with $81 \%$ accuracy.

In our study laparoscopy revealed additional findings in $25(50 \%)$ patients: most common being endometriosis in 6 (12\%) followed by bilateral hydrosalpinx in $5(10 \%)$, polycystic ovaries in $4(8 \%)$, ovarian cyst in $4(8 \%)$, intramural fibroid in $3(6 \%)$ and adhesions in $3(6 \%)$. Bulleti $\mathrm{C}$ et al $(2008)^{19}$ diagnosed endometriosis in $32 \%$ patients with laparoscopy. Richa Singh et al $(2012)^{20}$ in their laparoscopic study of infertile patients found abnormality in $68 \%$ cases: Peritoneal and peri-tubal adhesions in $29 \%$, phimosis / hydrosalpinx in $19 \%$, polycystic ovaries in $26 \%$, tubo-ovarian masses in $16 \%$, endometriosis in $4 \%$, congenital abnormalities in $10 \%$, myomas in $3 \%$, bilateral tubal blockage in $49 \%$ and unilateral tubal blockage in $17 \%$.

Transvaginal saline sonosalpingography diagnosed adnexal mass in $3(6 \%)$ patients and these on laparoscopy proved to be bilateral hydrosalpinx in 2 and endometrioma in 1. Laparoscopy picked bilateral hydrosalpinx in 3 more patients and 1 out of them had endometriosis as well. Endometriosis in 5 more patients and adhesions in 3 (6\%) were detected only on laparoscopy whereas submucous fibroid in $2(4 \%)$, polyp in $1(2 \%)$ and uterine septum in 1 (2\%) patient was diagnosed only on transvaginal saline sonosalpingography. Nabil M et al (2011) ${ }^{13}$ in their study found that transvaginal saline sonosalpingography and laparoscopy were similar in diagnosing polycystic ovaries but saline sonosalpingography did not detect adhesions.

In our study adverse event of transvaginal saline sonosalpingo-graphy included mild pelvic pain during injection of saline through the uterine cavity in $10(20 \%)$ patients. This did not, however, result in stopping the procedure or required any medication. No other immediate or remote complication was encountered by either transvaginal saline sonosalpingography or laparoscopy. Somchai Tanawattanacharoen et al $(2010)^{21}$ found that the most common complaint during sonosalpingography was pelvic pain in $36.66 \%$ patients followed by nausea in $5 \%$ and vaginal bleeding in $3.33 \%$. 


\section{Conclusion:-}

Transvaginal saline sonosalpingography is a simple, non-invasive, economical, well tolerated and reliable method for the assessment of tubal patency in an outpatient setting with minimal adverse effect. It may optimize the preoperative triage process for those women who require therapeutic intervention. However, laparoscopy is required especially in patients suspected to have endometriosis, adhesions, tuberculosis and other pelvic inflammatory diseases. It still remains the gold standard investigation in infertility as it is therapeutic as well.

\section{Bibliography:-}

1. Shaw's Textbook of Gynaecology. $15^{\text {th }}$ Edition, Ch. 17, Pg 180

2. Dutta DC. Textbook of gynaecology. $5^{\text {th }}$ edition. Infertility Ch. 16, Page 220.

3. Kore S, Hegde A, Nair S. Sonography for assessment of tubal patency: our experience. J Obstet and Gynecol India 2000; 50(2): 63-6.

4. Grant A. Infertility surgery of the Oviduct. Sertil Steril 1971; 22: 496-503.

5. Honore GM, Holden AE, Schenken RS. Pathophysiology and management of proximal tubal blockage. Fertil Steril 1999; 71: 785-795.

6. Westrom L, Jaesoef R, Reynolds G. Pelvic inflammatory disease and infertility: a cohort study of 1844 women with laparoscpically verified disease and 657 control women with normal laparoscopic results. Sex Trans Dis 1992; 19: 185-192.

7. Carry VH. Note on determination of patency of fallopian tubes by the use of collargol and x-ray shadow. Am J Obstet and Gynecol 1914; 69: 452.

8. Deichert U, Schlief R, van de Sandt M. Transvaginal hysterosalpingo-contrast sonography (Hy-Co-Sy) compared with conventional tubal diagnosis. Hum Reprod 1989; 4: 418.

9. Tufekci EC, Girit S, Bayirli E, Durmuşoğlu F, Yalti S. Fertility and Sterility 1992 Feb; 57(2): 336-40.

10. Volpi E, Diermatteo M, Zuccaro G. The role of transvaginal sonosalpingography in evaluation of tubal patency. Minerva Gynecological 1996; 48: 1-3.

11. Rubin IC. Diagnostic and Therapeutic effect of Kymographic uterotubal insufflation with comparative observations with hysterosalpingography. J Obstet Gynecol Br. Emp.1947;54:733

12. Junjira Suttipichate, Chullsak Sroywattana, Thewin Dejthevaporn, Pongthorn Virojchaiwong, Manit Sripramote. Transvaginal saline sonosalpingography for the assessment of tubal patency. Thai Journal of Obstetrics and Gynaecology September 2002; Vol. 14: PP. 223-229.

13. Nabil M, Tabbakh El, and Slamka Peter. Transvaginal Sonohysterography (Tv-Sh), Versus Hysterosalpingography (Hsg) and Laparoscopy. http://hcp.obgyn.net/laparoscopy/content/ article/1760982/1896801.

14. Seal Subrata Lall, Ghosh Debdatta, Saha Debdas, Bhattacharya Ajit Ranjan, Ghosh Subhash, Mitra Supratim. Comparative evaluation of sonosalpingography, hysterosalpingography, and laparoscopy for determination of tubal patency. J Obstet Gynecol India March/April 2007; Vol. 57, No. 2: page 158-161.

15. De Almeida L, Souzac C, Reginatto F, Cunha Filho JS, Facia A, Freitas F, Lavic Y, Passor EP. HYCOSY and HSG in diagnosis of tubal patency in infertility patients. Rev Assoc Med Bras 2000 Oct-Dec; 46(4): 342-5.

16. Zuo W, Wang F. Comparative study on assessment of tubal patency amon among tubal insufflations hydrotubation, HSG and laparoscopic chemotubation. Zhonghua Fu Chan Ke Za Zhi 1996 Jan; 31(1): 29-31.

17. Philippe Jeanty, Stephane Besnard, Amy Arnold, Cheryl Turner, Pam Crum. Air-contrast sonohysterography as a first step assessment of tubal patency. J Ultrasound Med 2000; 19: 519-527.

18. Fleischer AC, Vasquez JM, Cullinan JA, Eisenberg E. Sonohysterography combined with sonosalpingography: correlation with endoscopic findings in infertility patients. J Ultrasound Med. 1997 Jun; 16(6): 381-4.

19. Hajishafiha M, Zobairi T, Zanjani VR, Ghaesemi Rad M, Yekta Z, Mladkova N. Diagnostic value of sonohysterography in determination of fallopian tube patency as an initial step of routine infertility assessment. J Ultrasound Med 2009 Dec; 28(12): 1671-7.

20. Richa Singh, Saroj Singh, Poonam Yadav, Meenakshee Goyal. Journal of Evolution of Medical and Dental Sciences March 2013; Vol. 2, Issue 12: Pages 1792-98.

21. Tanawattanacharoen S, Suwajanakorn S, Uerpairojkit B, Boonkasemsanti W, Virutamasen P. Transvaginal Hysterosalpingo-Contrast Sonography (HyCoSy) Compared with Chromolaparoscopy. J Obstet Gynaecol Res. 2000 Feb;26(1):71-5. 